\title{
Coded String No Translations Data Type
}

National Cancer Institute

\section{Source}

National Cancer Institute. Coded String No Translations Data Type. NCI Thesaurus. Code C95636.

A data type comprised of a coded character string, which does not allow translations. 